\title{
Study on Optimization of Bagasse Hemicellulose Enzymolysis with Response Surface Analysis
}

\author{
Xiangyi Tang, Li Dai, Yanqiong Tang, Weidong Sun* \\ Institute of Light Industry and Food Engineering, Guangxi University, Nanning, China \\ Email: ${ }^{*}$ sunwd@gxu.edu.cn
}

Received 22 September 2014; revised 23 October 2014; accepted 27 November 2014

Copyright (C) 2014 by authors and Scientific Research Publishing Inc.

This work is licensed under the Creative Commons Attribution International License (CC BY). http://creativecommons.org/licenses/by/4.0/

c) (i) Open Access

\begin{abstract}
In order to enhance hydrolysis rate of bagasse, ultrasonic-assisted pretreatment is made in the experiment. The influence of addition of sulfuric acid, ultrasonic temperature, power and time to the hydrolysis of bagasse will be discussed in this paper. Optimal process and quadratic regression equation is obtained by using the response surface method. The yield of reducing sugar increases 6.5 percent after ultrasonic-assisted pretreatment. It demonstrates that the ultrasonic-assisted pretreatment can improve the hydrolysis rate of the bagasse.
\end{abstract}

\section{Keywords}

Ultrasonic, Bagasse, Response Surface

\section{Introduction}

Cellulose, hemicellulose and lignin are the main components of bagasse, and pentosan is a major ingredient of bagasse hemicellulose, whose hydrolysate mainly includes D-xylose, L-arabinose and D-glucose [1] [2].

An appropriate pretreatment can improve the yield of bagasse hydrolysis into monosaccharide. Kinds of methods have been adopted to assist hydrolysis, such as steam explosion, hot water treatment, organic solvent, dilute acid, dilute alkali, acid circulation, lime, ammonium fiber, frozen blasting and a circulation penetration [2][4], etc. Most of the pretreatments have special requirements for equipment as they require high temperature and high pressure, which is assumed to consume large energy and increase the cost of producing monosaccharide. Compared with approaches mentioned above, ultrasonic-assisted pretreatment can break the links of cell wall, be beneficial to release hemicellulose, improve the yield of monosaccharide, and reduce the cost of pretreatment

${ }^{*}$ Corresponding author.

How to cite this paper: Tang, X.Y., Dai, L., Tang, Y.Q. and Sun, W.D. (2014) Study on Optimization of Bagasse Hemicellulose Enzymolysis with Response Surface Analysis. Journal of Sustainable Bioenergy Systems, 4, 249-259.

http://dx.doi.org/10.4236/jsbs.2014.44023 
and enzymatic processes [5]-[7].

This paper mainly discussed the effect of the addition of sulfuric acid, temperature, power and time of the ultrasonic pretreatment to the bagasse enzymatic, and employed response surface analysis to optimize the process.

\section{Materials and Methods}

\subsection{Materials and Reagents}

Bagasse was obtained from the Refinery of Nanning Sugar Industry Co., Ltd. in Ming Yang, and was harvested by crushed 100 meshes followed by drying in the oven at $40^{\circ} \mathrm{C}$ for 1 day, and the dried bagasse was stored in the sample sack in a dryer until experiments; the xylanase was purchased from Sigma-Aldrich Co. LLC, and the optimum $\mathrm{pH}$ and temperature were 5.5 and $50^{\circ} \mathrm{C}$; the 3,5-Dinitrosalicylic acid (DNS ) was purchased from Sinopharm Chemical Reagent Co., Ltd.; and the D-xylose standard, acetic acid and sodium acetate were purchased from Aladdin Reagent Co., Ltd.

\subsection{Measurement of Reducing Sugar}

The DNS method was used to measure the content of the reducing sugar [8]; D-xylose was set as the standard; respectively took $2 \mathrm{~mL}$ from the D-xylose standard whose concentration is of $0 \mathrm{mg} / \mathrm{mL}, 0.4 \mathrm{mg} / \mathrm{mL}, 0.8 \mathrm{mg} / \mathrm{mL}$, $1.2 \mathrm{mg} / \mathrm{mL}, 1.6 \mathrm{mg} / \mathrm{mL}$ and $2 \mathrm{mg} / \mathrm{mL}$, and poured the liquid into each $25 \mathrm{~mL}$ volumetric, $1.5 \mathrm{~mL}$ the DNS reagent was added into each flask, and then, the chromogenic reaction was continued for 5 minutes, cooled rapidly in the stream, shook up and diluted with distilled water to $25 \mathrm{~mL}$ and measured the absorbance under $490 \mathrm{~nm}$ wavelength. Finally, Equation (1) was obtained according to the curves about D-xylose content and absorbance

$$
y=1.3805 x-0.0283
$$

\subsection{Ultrasonic-Assisted Pretreatment}

$0.5 \mathrm{~g}$ bagasse was weighed in a beaker and added $7.5 \mathrm{~mL} \mathrm{3 \% (w/v)} \mathrm{sulfuric} \mathrm{acid} \mathrm{solution.} \mathrm{Processed} \mathrm{the} \mathrm{sub-}$ stance during a period time of ultrasonic-assisted pretreatment under certain power and temperature (the value of power and temperature will be discussed below), and then adjusted its $\mathrm{pH}$ to 6.0 .

\subsection{Enzymolysis}

$40 \%(\mathrm{w} / \mathrm{w})$ xylanase was added to the bagasse solution which had been pretreated by ultrasonic. After enzymolysis for 12 hours under $50^{\circ} \mathrm{C}$, enzyme inactivation was proceeded by boiled for 10 minutes. Used centrifugal to separate, and then measured the component of reducing sugar from the supernatant.

\subsection{The Design of Response Surface Analysis Experiment}

It was found that the significant factors were ultrasonic power, ultrasonic time and ultrasonic temperature through the single factor experiment (3.2). The experimental design and the response surface were carried out in accordance with the single factor test results.

\subsection{Productive Rate of Reducing Sugar}

$$
\text { Reducing sugar yield }=\frac{\text { reducing sugar weight }}{\text { bagasse weight }} \times 100 \%
$$

\section{Results and Discussion}

\subsection{Effect of Different Pretreatment Methods on Enzymatic Reactions}

In order to select the optimal pretreatment between ultrasonic with acid, ultrasonic without acid and non-ultrasonic pretreatment, control the react time, power and temperature as 20 minutes, $30^{\circ} \mathrm{C}$ and $250 \mathrm{~W}$, and added $40 \%$ $(\mathrm{w} / \mathrm{w})$ xylanase for enzymolysis. The productive of reducing sugar of ultrasonic pretreatment in acid, ultrasonic with no acid and non-ultrasonic were $10.32 \%, 9.75 \%$ and $7.87 \%$. The pretreatment of ultrasonic in acid was 
better compared with non-ultrasonic or ultrasonic with no acid (Figure 1). It was because the ultrasonic could loose the construction of hemicellulose of bagasse [9]. And the enzyme and bagasse could contact easily; it causes an increased in the productive of reducing sugar. The efficiency of ultrasonic pretreatment in acid was more obvious due to its acceleration scission of the backbone and the side-chain of hemicellulose. Once enzyme binding sites further increased, enzymatic hydrolysis would achieve greater efficiency. Therefore ultrasonic pretreatment with acid was selected in this experiment.

\subsection{Single Factor Experiment}

In order to select three significant factors of ultrasonic-assisted with acid to enzymatic, the single factor experiment was processed. The ultrasonic time, power, temperature and the concentration of sulfuric acid were discussed separately.

\subsubsection{The Effect of Concentration of Sulfuric Acid to Enzymolysis}

$7.5 \mathrm{~mL}$ of different concentration of sulfuric acid from $2 \% \sim 6 \%(\mathrm{~W} / \mathrm{V})$ was added to 5 groups of bagasse, processed the substance during 20 minutes of ultrasonic-assisted pretreatment under $250 \mathrm{~W}$ ultrasonic power and $45^{\circ} \mathrm{C}$ ultrasonic temperature. After enzyme reaction, the growth rate of reducing sugar was not obvious with the concentration increased, and the productive of reducing sugar reached the peak value when the concentration was $5 \%(\mathrm{~W} / \mathrm{V}$ ) (Figure 2). $5 \%(\mathrm{~W} / \mathrm{V})$ sulfuric acid solution was selected to bagasse pretreatment, but the effect of sulfuric acid concentration to enzyme reaction was not significant.

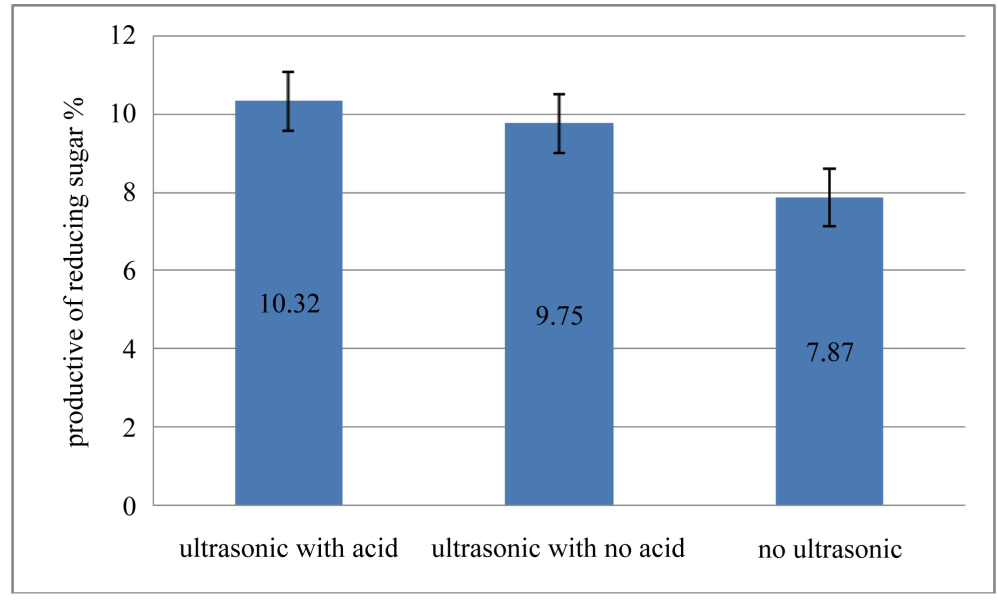

Figure 1. The effect of different types of pretreatments to the enzymolysis.

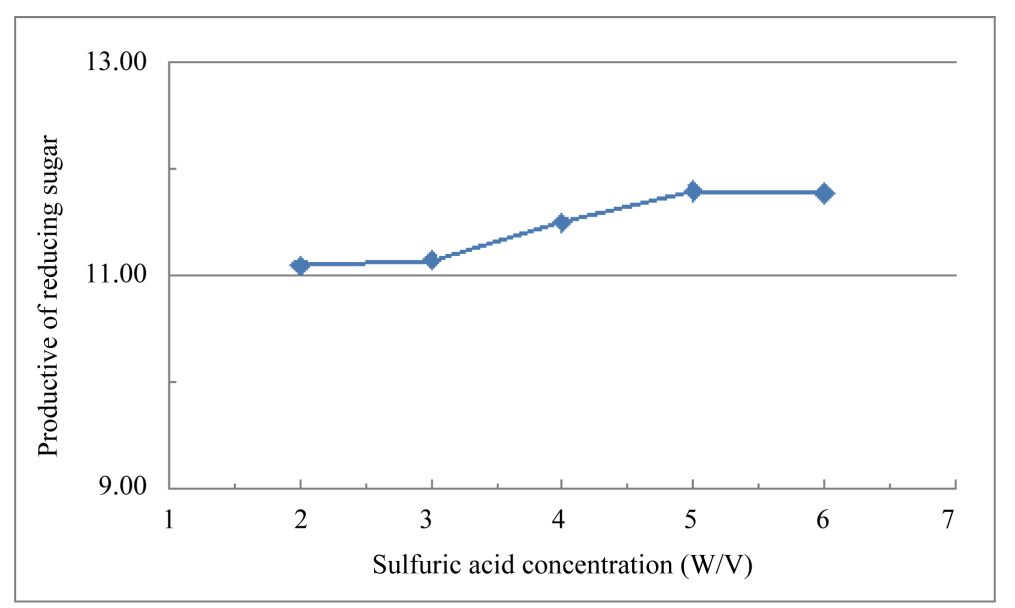

Figure 2. Influence of sulfuric acid concentration to enzyme reaction. 


\subsubsection{The Effect of Ultrasonic Power to Enzymolysis}

In the second group of single factor experiment, $7.5 \mathrm{~mL} 5 \%(\mathrm{w} / \mathrm{v})$ sulfuric acid solution was added to bagasse, the influence of ultrasonic power to enzyme reaction was discussed; the ultrasonic time and temperature were controlled at 20 minutes and $45^{\circ} \mathrm{C}$, after enzyme reaction, the relationship between productive of reducing sugar and ultrasonic power was shown in Figure 3. When the ultrasonic power was $200 \sim 300 \mathrm{~W}$, the productive of reducing sugar was growing fast. However with the power boost into $300 \sim 500 \mathrm{~W}$, the productive of reducing sugar was essentially flat. It is mainly because the power under $300 \mathrm{~W}$ is not enough to break the secondary bonds which maintain the construction of bagasse. When the ultrasonic power was reached a certain value $(\geq 300$ $\mathrm{W})$, all the secondary bonds which could be broke by ultrasonic had been broken, the productive of reducing sugar reached the balance. Above all, $300 \mathrm{~W}$ was selected to bagasse pretreatment.

\subsubsection{The Effect of Ultrasonic Time to Enzymolysis}

Bagasse was divided into five groups and added $7.5 \mathrm{~mL} 5 \%(\mathrm{~W} / \mathrm{V})$ concentration of sulfuric acid to each of them. Processed the substance under $250 \mathrm{~W}$ ultrasonic power and $45^{\circ} \mathrm{C}$ ultrasonic temperature, the ultrasonic time of each ranged from $20 \sim 70$ minutes. After enzyme reaction, the relationship between productive of reducing sugar and ultrasonic power was shown in Figure 4. When the ultrasonic time was $20 \sim 40$ minutes, the content of reducing sugar was growing fast. However with the time boost into $40 \sim 70$ minutes, the productive of reducing sugar was essentially flat. The productive of reducing sugar reached the balance value when the ul-

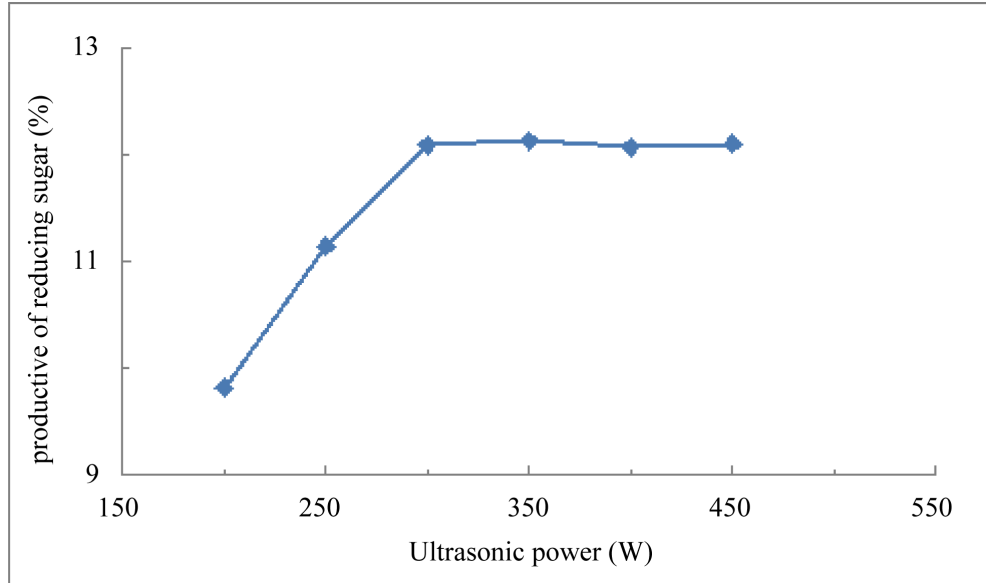

Figure 3. Influence of ultrasonic power to enzyme reaction.

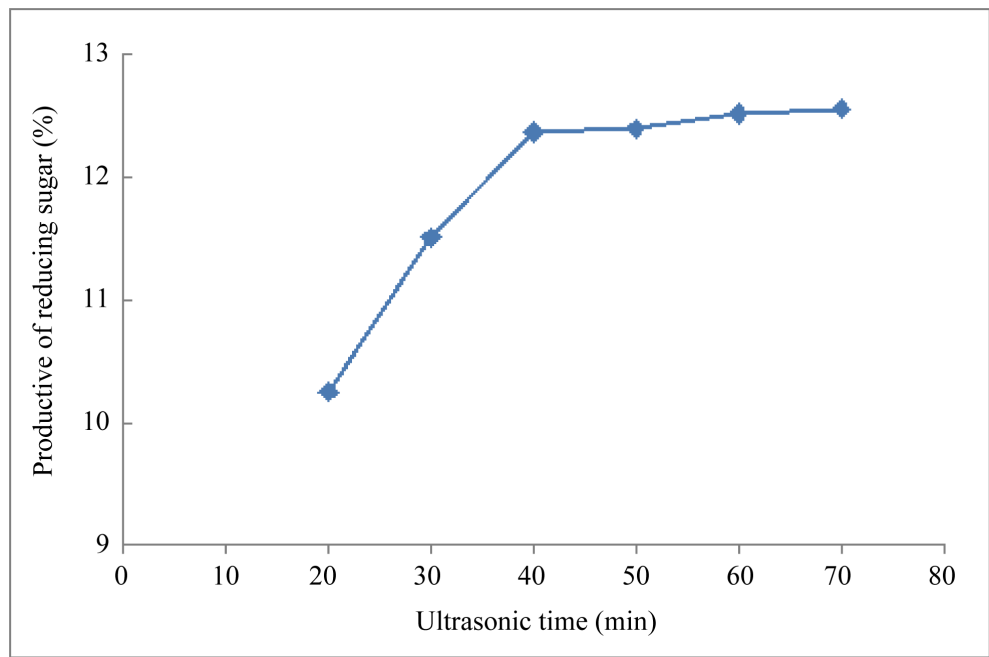

Figure 4. Influence of ultrasonic time to enzyme reaction. 
trasonic time was 40 minutes. It was because the number of broken secondary bonds was rising rapidly as the ultrasonic time increased, its loose construction will increase the binding sites of xylanase. But 40 minutes was enough to break most of the secondary bonds which ultrasonic could break.

\subsubsection{The Effect of Ultrasonic Temperature to Enzymolysis}

In the forth group of single factor experiment, $7.5 \mathrm{~mL} 5 \%(\mathrm{w} / \mathrm{v})$ sulfuric acid solution was added to bagasse, the influence of ultrasonic temperature to enzyme reaction was discussed; the ultrasonic time and power were controlled at 60 minutes and $300 \mathrm{~W}$, after enzyme reaction, the relationship between productive of reducing sugar and ultrasonic power was shown in Figure 5. When the ultrasonic temperature was $25^{\circ} \mathrm{C} \sim 55^{\circ} \mathrm{C}$, the productive of reducing sugar was growing fast. With the temperature boost into $55^{\circ} \mathrm{C} \sim 75^{\circ} \mathrm{C}$, the productive of reducing sugar was essentially flat. All above, the ultrasonic temperature has a significant effect as ultrasonic time and power.

\subsection{The Selection of Factors and Levels for Response Surface Analysis}

Monosaccharide and oligosaccharide (belong to the reducing sugar) are the main hydrolyzate of bagasse hemicellulose, and D-xylose is the main components of monosaccharide. Therefore the content of reducing sugar could adequately reflect the depolymerization degree of bagasse hemicellulose, it was selected as response value. Based on the result of the single factor, ultrasonic time, power, and temperature were selected as three significant factors of ultrasonic-assisted with acid to enzymatic bagasse. The response surface optimization method with 3 factors * 3 levels was used and the experimental program was shown in Table 1.

\subsection{Response Surface Experimental Design and Results}

The ultrasonic time, temperature and power were selected as variable factors, and reducing sugar as their response value. The experimental program and results were shown in Table 2.

\subsection{Response Surface Diagram}

Took ultrasonic time (A), temperature (B), power (C) as response factors, and the contents of reducing sugar as

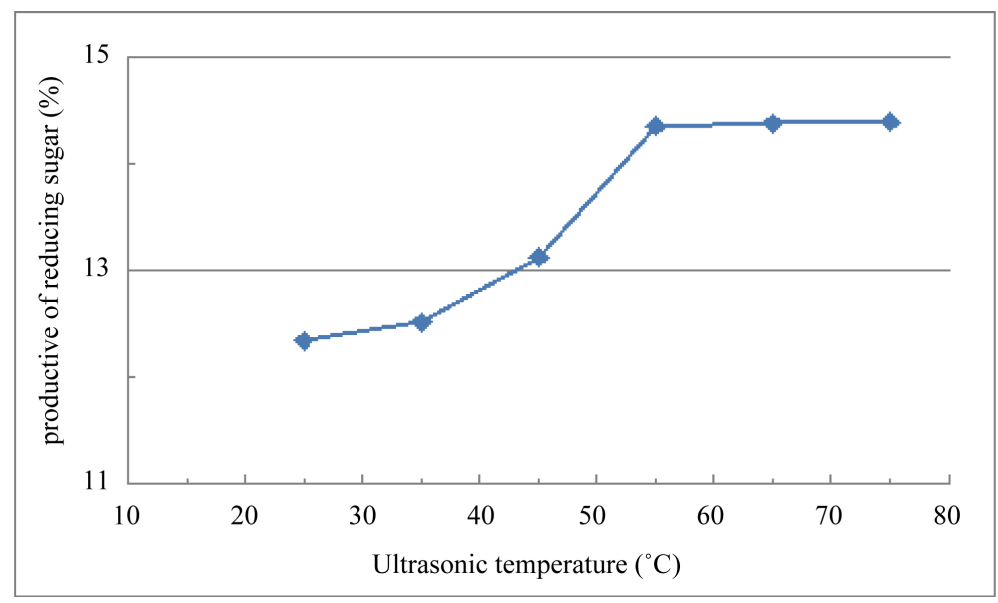

Figure 5. Influence of ultrasonic temperature to enzyme reaction.

Table 1. Factors and levels.

\begin{tabular}{cccc}
\hline & & \multicolumn{2}{c}{ Factors } \\
\cline { 2 - 4 } Levels & A Time min & B Temperature ${ }^{\circ} \mathrm{C}$ & 250 \\
0 & 20 & 55 & 300 \\
1 & 40 & 65 & 350 \\
\hline
\end{tabular}


Table 2. Response surface experimental design and results.

\begin{tabular}{ccccc}
\hline No. & A Time min & B Temperature ${ }^{\circ} \mathrm{C}$ & C Power W & Content \% \\
\hline 1 & 40.00 & 65.00 & 350.00 & 14.45 \\
2 & 60.00 & 55.00 & 250.00 & 13.09 \\
3 & 60.00 & 65.00 & 300.00 & 14.39 \\
4 & 40.00 & 45.00 & 250.00 & 12.07 \\
5 & 20.00 & 55.00 & 250.00 & 12.52 \\
6 & 40.00 & 45.00 & 350.00 & 13.13 \\
7 & 60.00 & 45.00 & 300.00 & 14.38 \\
8 & 60.00 & 55.00 & 300.00 & 12.84 \\
9 & 20.00 & 65.00 & 350.00 & 14.32 \\
10 & 40.00 & 55.00 & 300.00 & 12.10 \\
11 & 20.00 & 45.00 & 300.00 & 14.36 \\
12 & 40.00 & 55.00 & 300.00 & 14.35 \\
13 & 40.00 & 55.00 & 300.00 & 14.32 \\
14 & 40.00 & 55.00 & 300.00 & 14.29 \\
15 & 40.00 & 55.00 & 300.00 & 12.37 \\
16 & 20.00 & 55.00 & 350.00 & 13.04 \\
17 & 40.00 & 65.00 & 250.00 & \\
\hline
\end{tabular}

response value, and used Design-Expert V8.0.6 software to analyze the experimental data. The response surface diagrams and contour maps were shown as Figure 6.

\subsection{Variance Analysis}

The regression equation of the content of reducing sugar in bagasse enzymolysis solution after ultrasonic treatment was obtained by Design-Expert V8.0.6. The content of reducing sugar in enzymolysis solution $=14.32+$ $0.70 \times \mathrm{A}+0.58 \times \mathrm{B}+0.40 \times \mathrm{C}+0.13 \times \mathrm{A} \times \mathrm{B}+0.25 \times \mathrm{A} \times \mathrm{C}+0.31 \times \mathrm{B} \times \mathrm{C}-0.66 \times \mathrm{A}^{2}-0.55 \times \mathrm{B}^{2}-0.68 \times$ $\mathrm{C}^{2}$.

The $\mathrm{F}$ value of this model is 153.35 (Table 3 ). If the $\mathrm{P}$ value is less than 0.05 , the factor should be significant. From the result of Variance analysis we can conclude that the optimizing model is highly significant, and also the lack of fit is non-significant ( $\mathrm{P}$-value $=0.0566>0.05$ ), it is illustrate that the equation fit the experiment well.

Figure 6 can intuitively reflect the impact of various factors on the response value. All the three response surface diagrams above have extreme points (the highest point of response surface). It was demonstrated that the maximum of productive of reducing sugar will exist above the selected condition. The shape of contour maps (c2) showed a most positive interaction between ultrasonic temperature and power followed by ultrasonic time and power (b2) (the significance of interactive factor depends on the ellipse degree of the contour). The shape of the contour between ultrasonic time and temperature in Figure 6(a2) indicated a moderate interaction. In accordance of the variance analysis (ANOVA) data (Table 3), the P value of the interactive effect between temperature and time, temperature and power, time and power on reducing sugar productive were significant $(\mathrm{P}$ value $<$ $0.05)$, but the smaller $P$ value is, the more impact on reducing sugar productive, the influence order of interactive factor on yield of reducing sugar were power and temperature $(\mathrm{P}=0.0005)>$ power and time $(\mathrm{P}=0.0018)>$ time and temperature $(\mathrm{P}=0.0372)$. Otherwise, ultrasonic time $(\mathrm{F}$ value $=383.14)$ is the most significant factor among the three according to the $\mathrm{F}$ value of Variance analysis (the higher $\mathrm{F}$ value is, the more significant of single factor $[10]$, followed by temperature $(\mathrm{F}$ value $=258.72)$ and power $(\mathrm{F}$ value $=121.56)$.

The higher of R-squared value, and the closer Pred R-squared value and Adj R-squared value, the higher 


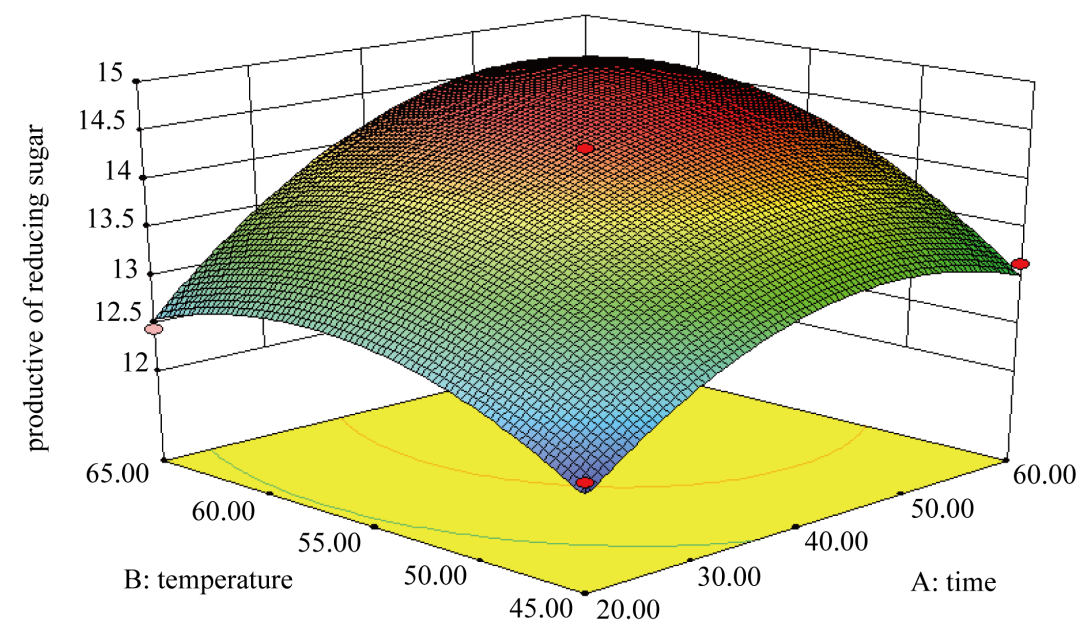

(a1)

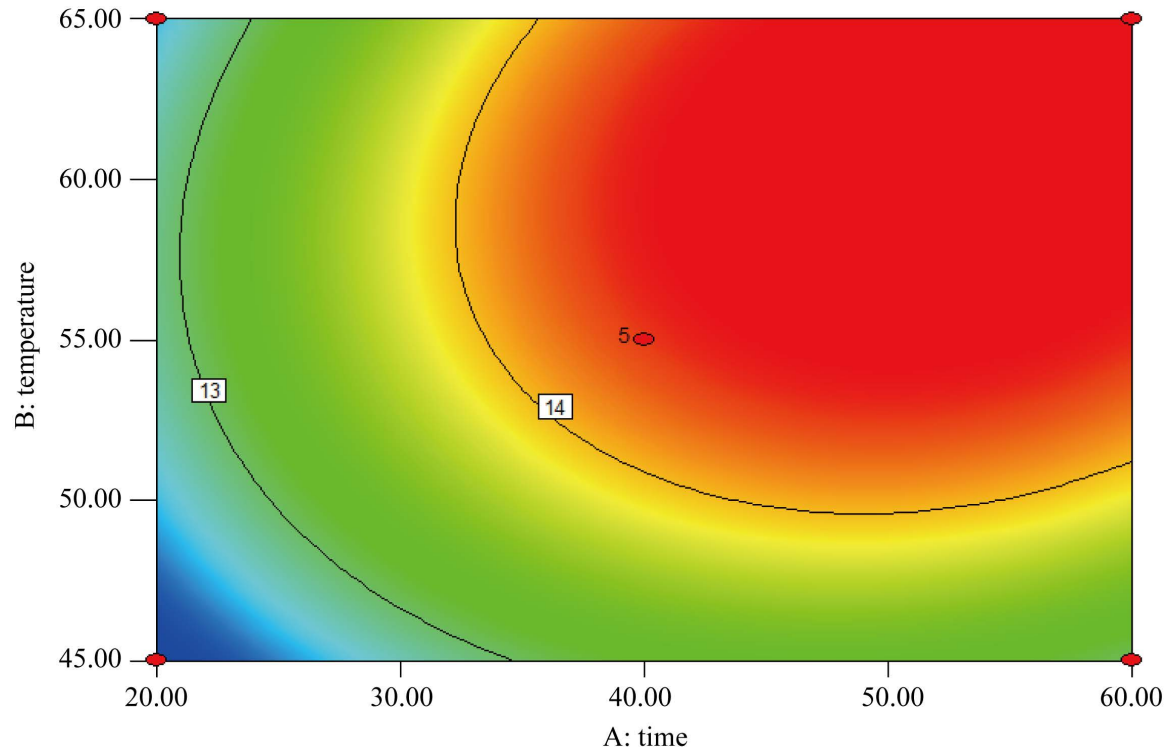

(a2)

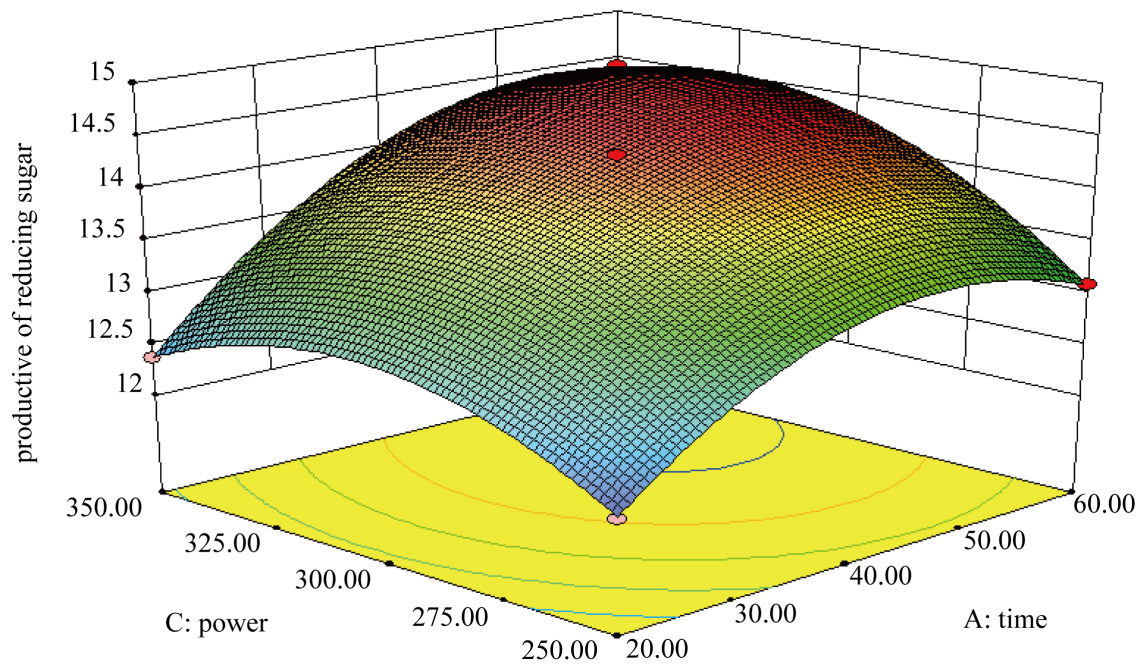

(b1) 


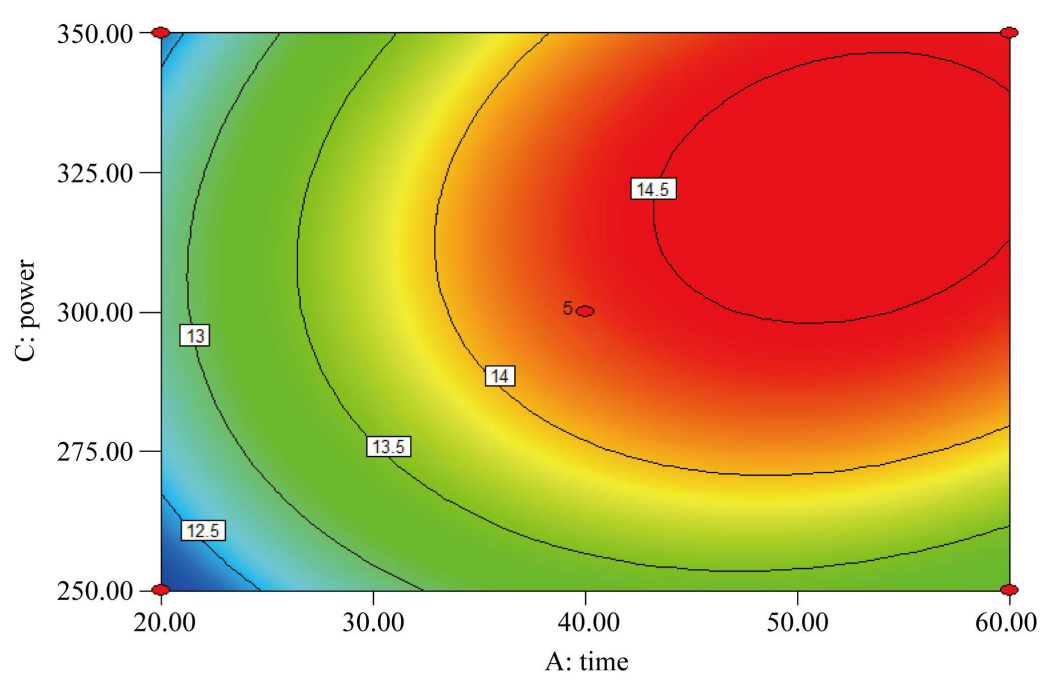

(b2)

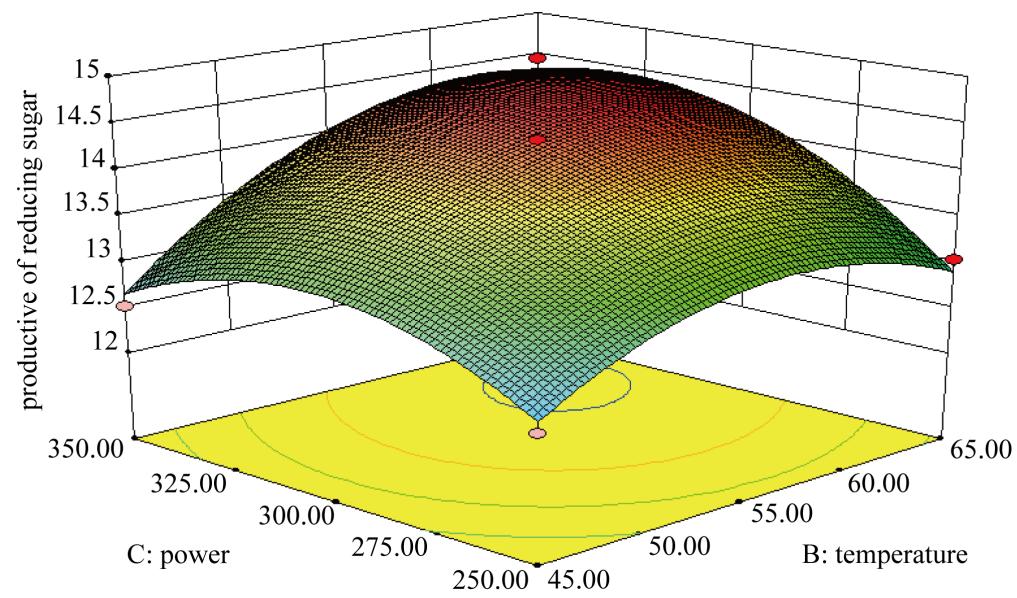

(c1)

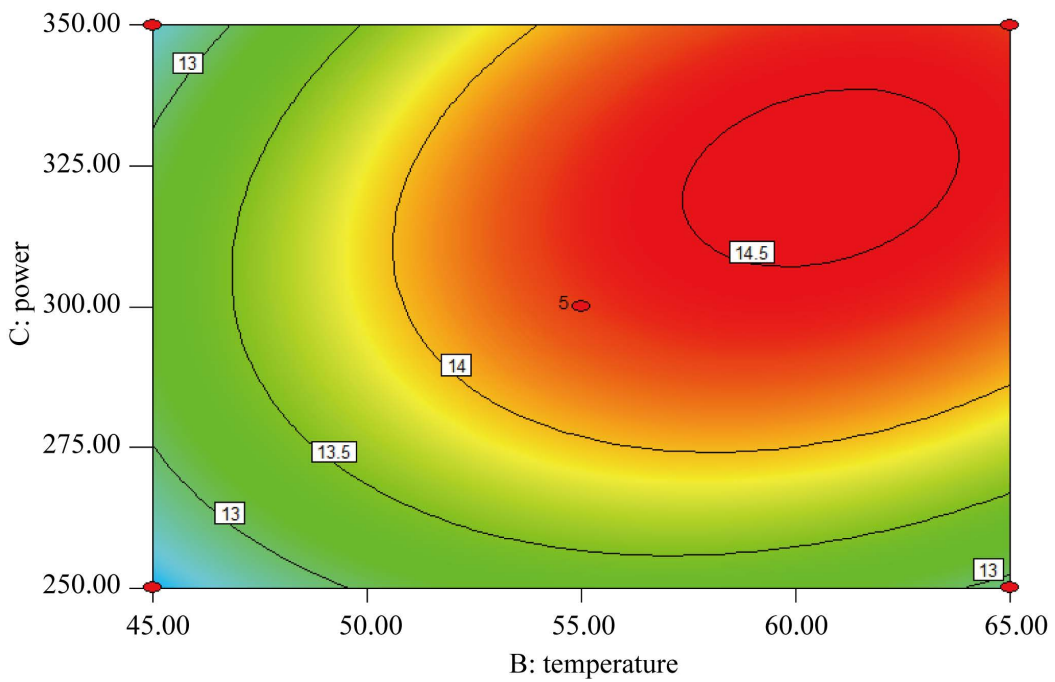

(c2)

Figure 6. The 3D diagrams and contour maps of the relationship between content and various factors: (a1) (a2) time and temperature; (b1) (b2) power and time; (c1) (c2) power and temperature. 
Table 3. Variance analysis.

\begin{tabular}{ccccccc}
\hline Factor & Sum of Square & DOF & Mean Square & F Value & $\begin{array}{c}\text { P Value } \\
\text { Prob }>\text { F }\end{array}$ & Significant \\
\hline Model & 14.17 & 9 & 0.57 & 153.38 & $<0.0001$ & Highly significant \\
A & 3.93 & 1 & 3.93 & 383.14 & $<0.0001$ & Highly significant \\
B & 2.66 & 1 & 2.66 & 258.72 & $<0.0001$ & Highly significant \\
C & 1.25 & 1 & 1.25 & 121.56 & $<0.0001$ & Highly significant \\
AB & 0.068 & 1 & 0.068 & 6.58 & 0.0372 & Significant \\
AC & 0.25 & 1 & 0.25 & 23.86 & 0.0018 & Significant \\
BC & 0.39 & 1 & 0.39 & 38.04 & 0.0005 & Significant \\
A2 & 1.83 & 1 & 1.83 & 178.63 & $<0.0001$ & Highly significant \\
B2 & 1.25 & 1 & 1.25 & 121.80 & $<0.0001$ & Highly significant \\
C2 & 1.96 & 1 & 1.96 & 191.01 & $<0.0001$ & Highly significant \\
Residual & 1.2681 & 7 & 0.1812 & & & Not significant \\
Lack of fit & 1.1869 & 3 & 0.3956 & 20.97 & 0.0566 & \\
Pure error & 0.0812 & 4 & 0.0203 & & & \\
Total residual & 14.25 & 16 & & & & \\
\hline
\end{tabular}

SNR Adeq Precision value indicates a better goodness of fit of the model. In terms of this model, the value of Rsquared is 0.995 (Table 4), which relatively high; the Pred R-squared value is 0.9319 , and the Adj R-squared value is 0.9885 , Pred R-squared and Adj R-squared Pred value nearly being equal; the value of Adeq Precision is 35.876; all the above shows that the model fits well.

The picture of normal plot residual is used to indicate the gap between the real value and the forecast value. If the values above are as far as possible in the same line, it will show a well goodness of fit. From Figure 7 we can find that most of the points are in line, which represents a well goodness of fit to this model.

From the RSM analysis system we could obtain that the best conditions of bagasse enzymatic hydrolysis were the cases when the time was 53.07 minutes, $62.2^{\circ} \mathrm{C}$ temperature and $300.71 \mathrm{~W}$ power and predicted that the productive of reducing sugar is $14.7008 \%$. It was also found that the ultrasonic time and temperature had a highly promotion than the optimum of single factor measurement of ultrasonic, and ultrasonic power had a slight increased at the same time.

\subsection{Model Verification}

In order to validate the situation between model and accurate, the bagasse enzyme hydrolysis experiment was repeated three times in the condition of 53.07 minutes ultrasonic time, $62.2^{\circ} \mathrm{C}$ ultrasonic temperature, and 300.71 $\mathrm{W}$ ultrasonic power, and predicted that the content of reducing sugar under this condition is $14.7 \%$. Took the average of the three is $14.4 \%$, and the error of predict value being $0.3 \%$, it showed that the optimization results and model were reliable. The result of content of reducing sugar was $6.5 \%$ higher than that without ultrasonic bagasse enzymatic hydrolysis.

\section{Conclusion}

Compared with non-ultrasonic pretreatment, the content of reducing sugar of ultrasonic pretreatment enzymatic hydrolysis had increased. Electing three significant factors from the result of single factor experiment of ultrasonic pretreatment to optimization process with response surface, and then the optimal conditions of ultrasonic pretreatment enzymatic hydrolysis were obtained-53.07 minutes ultrasonic time, $62.2^{\circ} \mathrm{C}$ ultrasonic temperature and $300.71 \mathrm{~W}$ ultrasonic power. Repeating the experiment three times under the optimal condition, and then the average content of reducing sugar of enzymatic bagasse was $14.421 \%$. In the next step, we obtained a quadratic equation model of significant regression about ultrasonic power, time, temperature and the content of reducing 
Table 4. The goodness of fit parameters.

\begin{tabular}{cccc}
\hline R-Squared & Pred R-Squared & Adj R-Squared & Adeq Precision \\
0.9950 & 0.9193 & 0.9885 & 32.876 \\
\hline
\end{tabular}

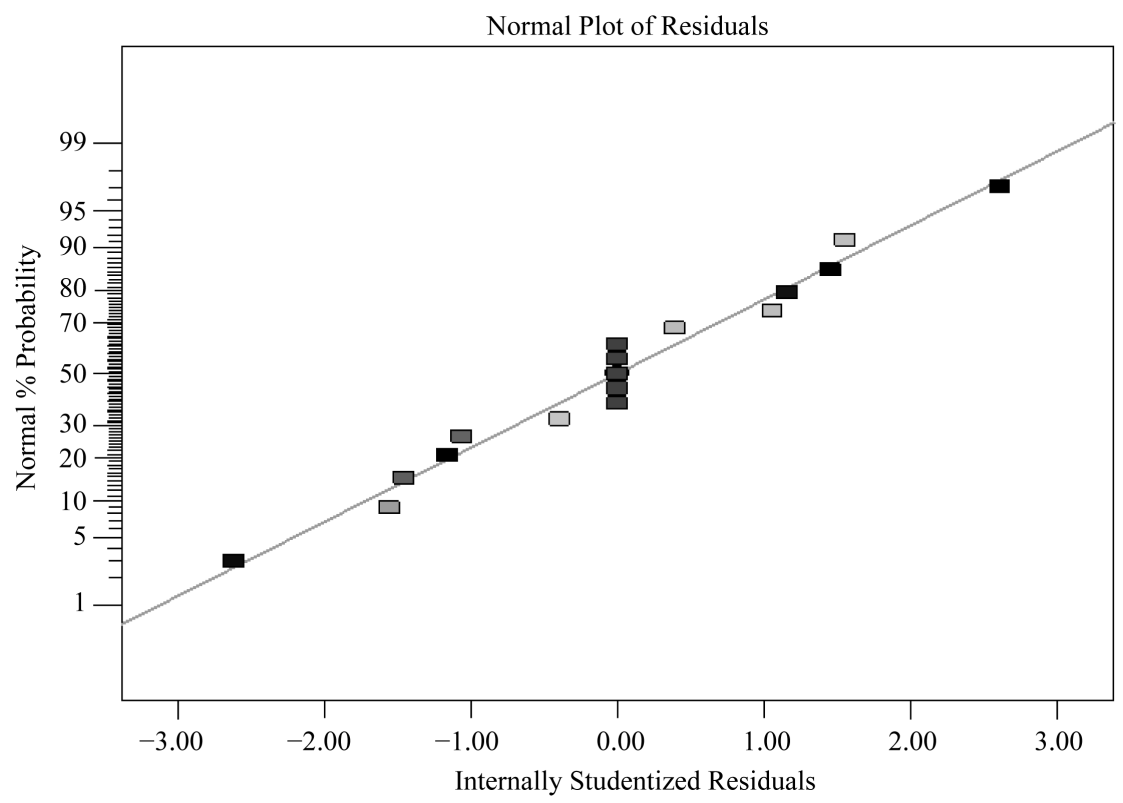

Figure 7. Normal plot of residuals.

sugar, and the result of content of reducing sugar under this process was $6.5 \%$ higher than that without ultrasonic bagasse enzymatic hydrolysis.

\section{Acknowledgements}

The materials and data are based on the experiment through the Institute of Light Industry and Food Engineering at Guangxi University, the Sugar Engineering and Technology Research Center at Guangxi University. We acknowledge the contribution of Miss Yan-rung Zhu.

\section{References}

[1] Pei, J., Xue, Y. and Zhao, L. (2003) Review of Studies on Arabinofuranosidase. The Journal of Microbiology, 30, 9194.

[2] Pérez, J., Muñoz-Dorado, J., de la Rubia, T. and Martínez, J. (2002) Biodegradation and Biological Treatments of Cellulose, Hemicellulose and Lignin: An overview. International Microbiology, 5, 53-63. http://dx.doi.org/10.1007/s10123-002-0062-3

[3] Wyman, C.E., Dale, B.E. and Elander, R.T. (2005) Coordinated Development of Leading Biomass Pretreatment Technologies. Bioresource Technology, 96, 1959-1966. http://dx.doi.org/10.1016/j.biortech.2005.01.010

[4] Liu, G. and Wyman, C.E. (2005) Partial Flow of Compressed-Hot Water through Corn Stover to Enhance Hemicellulose Sugar Recovery and Enzymatic Digestibility of Cellulose. Bioresource Technology, 96, 1978-1985.

[5] Tang, A., Zhang, H. and Chen, G. (2005) Influence of Ultrasound Treatment on Accessibility and Regioselective Oxidation Reactivity of Cellulose. Ultrasonics Sonochemistry, 12, 467-472. http://dx.doi.org/10.1016/j.ultsonch.2004.07.003

[6] Liu, L., Zong, Z. and Qiu, Z. (2008) Study on Ultrasonic Promote Hydrolysis of Cellulose Preparation of Fermentable Reducing Sugar. Journal of Changshu Institute of Technology, 22, 77-81.

[7] Gronroos, A., Kyllonen, H. and Korpijarvi, K. (2005) Ultrasound Assisted Method to Increase Soluble Chemical Oxygen Demand (SCOD) of Sewage Sludge for Digestion. Ultrasonics Sonochemistry, 12, 115-120. http://dx.doi.org/10.1016/j.ultsonch.2004.05.012 
[8] Zhao, K., Xu, J. and Gu, Y. (2008) Study on Determination of Reducing Sugar Content Using 3,5-Dinitrosalicylic Acid Method. Food Science, 29, 534-536.

[9] Qin, M., Wu, M. and Liu, Y. (2009) Study on Enhancing the Enzymatic Digestibility of Bagasse by Ultrasonic-Assisted Alkali Pretreatment. Renewable Energy Resource, 27, 28-32.

[10] Yin, Z.L.R. and Han, X. (2008) Optimization of the Extraction Technique of Morus Polysaccharide via Response Surface Analysis. Journal of Chinese Institute of Food Science and Technology, 8, 39-45. 
Scientific Research Publishing (SCIRP) is one of the largest Open Access journal publishers. It is currently publishing more than 200 open access, online, peer-reviewed journals covering a wide range of academic disciplines. SCIRP serves the worldwide academic communities and contributes to the progress and application of science with its publication.

Other selected journals from SCIRP are listed as below. Submit your manuscript to us via either submit@scirp.org or Online Submission Portal.
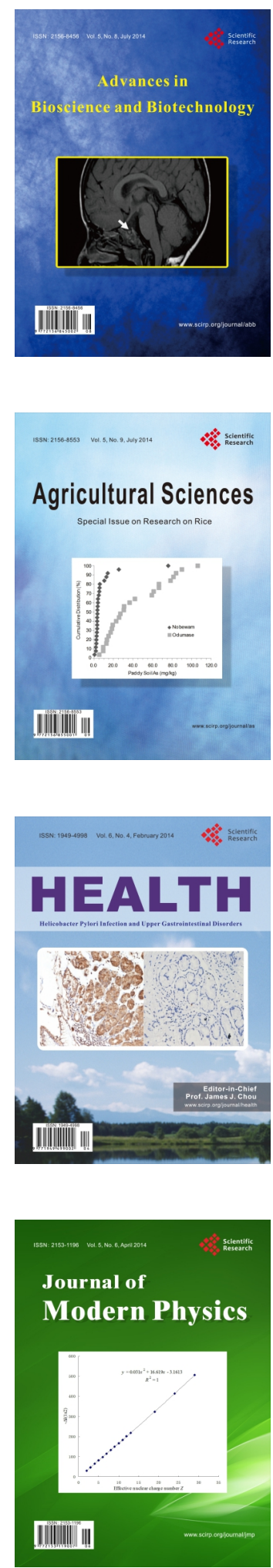
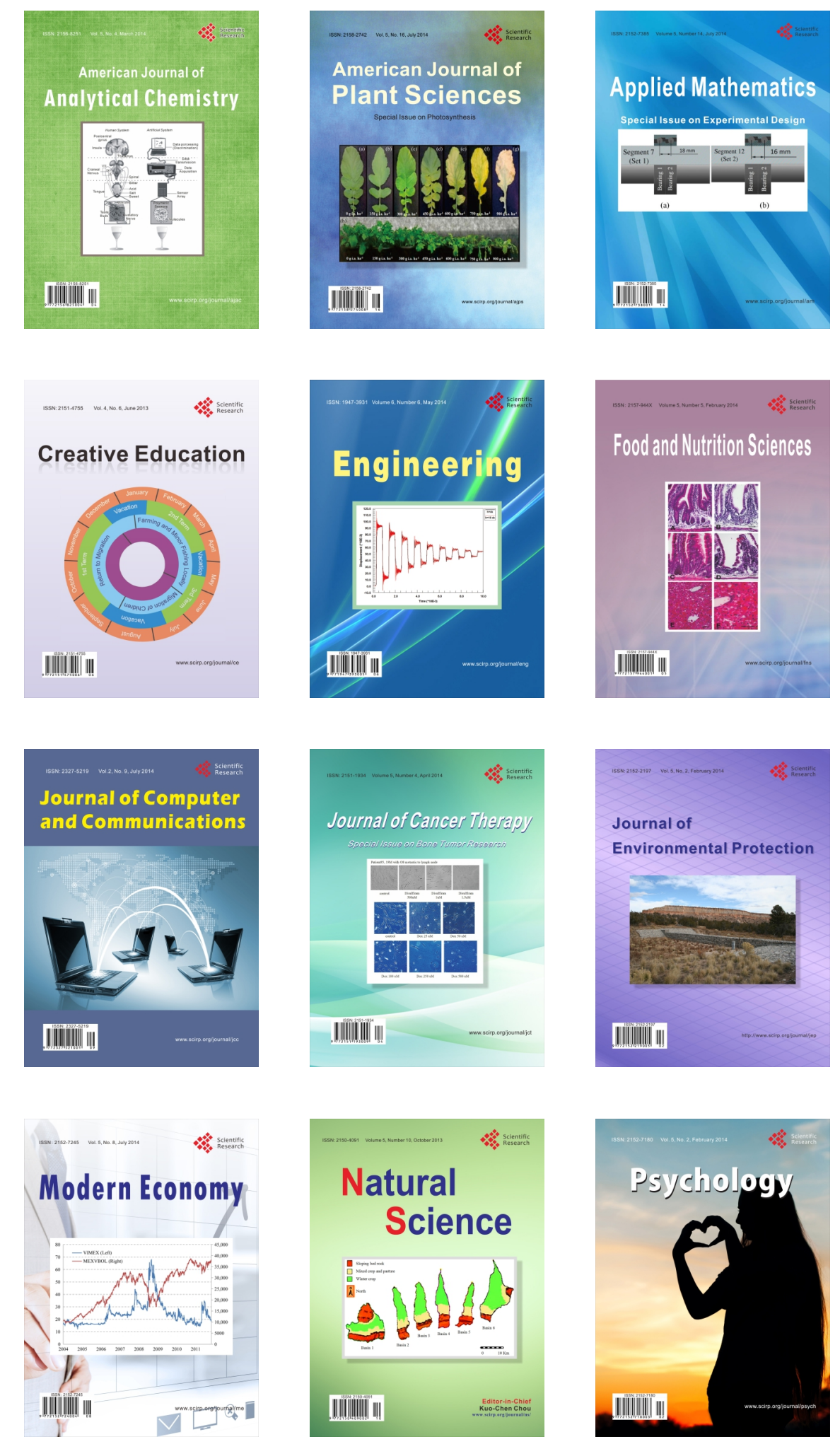